\title{
HYDRAULIC CONDUCTIVITY VARIABILITY IN HORIZONTAL SUBSURFACE FLOW CONSTRUCTED WETLANDS
}

Doi:http://dx.doi.org/10.1590/1809-4430-Eng.Agric.v37n2p333-342/2017

\section{GHEILA C. F. BAPTESTINI ${ }^{1}$, ANTONIO T. MATOS ${ }^{*}$, MAURO A. MARTINEZ ${ }^{1}$, ALISSON C. BORGES ${ }^{1}$, MATEUS P. MATOS ${ }^{3}$}

${ }^{2 *}$ Corresponding author. Universidade Federal de Minas Gerais/ Belo Horizonte - MG, Brasil. E-mail: atmatos@ desa.ufmg.br

ABSTRACT: Many modifications in hydrodynamic conditions occur inside the bed of a horizontal subsurface flow constructed wetland (HSSF-CW) in operation. Studies on hydraulic conductivity measurement techniques in HSSF-CW are imperative since the monitoring of flow conditions is essential for understanding and controlling its clogging. This study aimed to assess the hydrodynamic behavior in HSSF-CW by means of saturated hydraulic conductivity $\left(K_{s}\right)$ analysis. For this, six HSSF-CW were used: two non-cultivated (control), two cultivated with Tifton 85 (Cynodon spp.), and two cultivated with alligator weed (Alternanthera philoxeroides). Application of swine wastewater (SW) in HSSF-CW started on June 15, 2011, with $K_{s}$ measurement period between September 9 and November 11, 2011, in which five measurements were performed in different positions along the system length and over experimental period in order to assess the effects of vegetation, position, and time factors on this variable. $K_{s}$ values ranged from 1,392 to $2,834 \mathrm{~m} \mathrm{~d}^{-1}$. Plant presence led to $K_{s}$ decreasing in the systems, but cultivated species had no influence on this variable. Monitoring time of HSSF-CW was no longer enough to provide a reduction in $K_{s}$, at $10 \%$ probability level.

KEYWORDS: hydrodynamic conditions, clogging, constructed wetlands, wastewater treatment.

\section{INTRODUCTION}

Wastewater treatment in horizontal subsurface flow constructed wetland (HSSF-CW) is widely used for removing pollutants from effluents worldwide. In contrast to conventional sewage treatment technologies, HSSF-CW present simple and efficient treatment mechanisms, as well as few maintenance and operation requirements (FIA et al., 2010; NIVALA et al., 2012; PRATA et al., 2013).

Over HSSF-CW operating time, removal mechanisms by filtration, sedimentation, adsorption, precipitation, and microbial degradation occur (KNOWLES et al., 2010), providing solid accumulation between particles that compose the filter bed. This phenomenon of obstructing the porous spaces is denominated clogging and it is the main HSSF-CW operational problem.

Porous medium obstruction may be associated with suspended solids in wastewater applied to the system, formed biomass, suspended mineral solid deposition, refractory organic material accumulation, and chemical precipitate formation (KNOWLES et al., 2011; PEDESCOLL et al., 2011b). Porous medium clogging of HSSF-CW by plant roots and rhizomes is still the subject of controversy since some authors consider that these plant organs promote a pumping or suspension of support material (BRASIL; MATOS, 2008) in order to create a porous volume equivalent or higher than that previously existing in the medium. A few studies have indicated root presence as the reason for surface flow problems, in some cases, being attributed to porous medium clogging (FU et al., 2013; PAOLI; VON SPERLING, 2013).

According to NIVALA et al. (2012), there are three ways of assessing the impact extent by porous medium clogging, indicating its obstruction degree. One of them consists of quantifying the amount of solids within the pores (PEDESCOLL et al., 2011a). Another is the use of tracers and monitoring of its concentration to define the hydraulic detention time (HDT) and hydrodynamic

\footnotetext{
${ }^{1}$ Universidade Federal de Viçosa/ Viçosa - MG, Brasil.

${ }^{3}$ Universidade Federal de Lavras/ Lavras - MG, Brasil.

Received in: 11-10-2015

Accepted in: 9-27-2016
} 
conditions within the medium (BORGES et al., 2009; COTA et al., 2011). Finally, there is the measurement of saturated hydraulic conductivity $\left(K_{s}\right)$, which varies with the operating time of a treatment unit.

Porous space obstruction of HSSF-CW modifies the medium hydrodynamic conditions, notably with respect to $K_{s}$. As the occlusion of interstitial spaces advances, an increase in load loss is observed, especially in the system's initial region, leading to a decrease in $K_{s}$ and, consequently, surface flow occurrence, with possible decrease in treatment system efficiency (KNOWLES et al., 2011; PEDESCOLL et al., 2013). This possibly makes the hydraulic conductivity a variable with a strong association with porous medium clogging.

However, $K_{s}$ determination in $\mathrm{HSSF}-\mathrm{CW}$ bed is difficult since it undergoes the influence of out-of-control factors such as surface flow and short circuits, in addition to porosity obstruction because of growth variations and degradation of roots and/or accumulation/degradation of solid residues in $\mathrm{HSSF}-\mathrm{CW}$.

Because studies on clogging process in HSSF-CW have only been widely reported in the scientific literature in recent years (COTA et al., 2011; KNOWLES et al., 2011; XU et al., 2013), $K_{s}$ in situ measurements are still developing technologies. Thus, studies that provide the improvement of $K_{s}$ measurement techniques in $\mathrm{HSSF}-\mathrm{CW}$ are imperative since the monitoring of hydrodynamic conditions of these systems is essential for their operational improvement.

Considering that, this study aimed to assess the hydrodynamic behavior in HSSF-CW systems used for swine wastewater (SW) treatment by means of $K_{s}$ monitoring along cultivated and non-cultivated systems during wastewater application period.

\section{MATERIAL AND METHODS}

\section{Structure and experimental conditions}

The experiment was conducted at the Federal University of Viçosa (UFV), Viçosa, MG, Brazil from September 9 to November 11, 2011. The experimental structure consisted of six HSSF$\mathrm{CW}$ maintained in a greenhouse to perform SW treatment.

HSSF-CW systems were composed of pilot-scale fiberglass boxes with dimensions of $0.6 \times$ $0.5 \times 2.0 \mathrm{~m}$ in height, width, and length, respectively, installed on the ground and with no bottom slope, as presented in Figure 1. HSSF-CW systems were filled with gravel $\left(\mathrm{D}_{60}=9.1 \mathrm{~mm}\right.$, the coefficient of uniformity $\mathrm{Cu} \mathrm{D}_{60} / \mathrm{D}_{10}=3.1$, and initial void volume of $0.398 \mathrm{~m}^{3} \mathrm{~m}^{-3}$ ), used as a support medium with a height of $0.55 \mathrm{~m}$, and the water level was maintained at $0.05 \mathrm{~m}$ below the support medium surface. At each experimental unit outlet, we installed a drainage system composed of a 32-mm diameter PVC pipe.
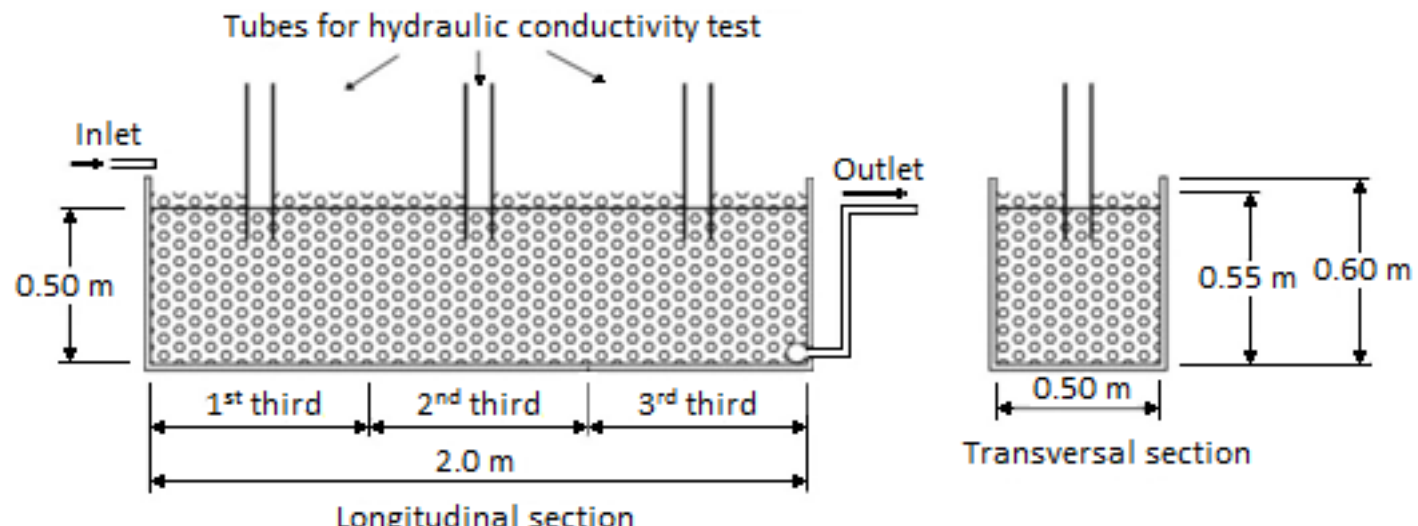

FIGURE 1. Scheme of longitudinal and transversal sections of HSSF-CW with their respective dimensions. 


\section{Wastewater used}

SW used in the experiment, resulting from washing animal stall, passed through a sand trap, masonry tank, sieve, and grease trap, being subsequently collected and transferred to a hogsheadtype transport tank with a capacity for $2000 \mathrm{~L}$. These collections were carried out twice a week and transported to UFV, where the experiment was installed.

From the hogshead tank, SW was transferred to a temporary reservoir (2000 L), being pumped daily into polyethylene boxes with a capacity of $320 \mathrm{~L}$. Subsequently, wastewater was transferred to equalization tanks and later distributed to HSSF-CW systems by metering-solenoid peristaltic pumps ProMinent ${ }^{\circledR}$ CONCEPT (flow rate in the range from 0.7 to $23 \mathrm{~L} \mathrm{~h}^{-1}$ ) and PVC hoses.

During the experimental period, six simple samples of SW affluent to the HSSF-CW systems $\left(\mathrm{SW}_{\mathrm{A}}\right)$ were collected and characterized according to the Standard Methods for the Examination of Water and Wastewater (APHA et al., 2012). Table 1 shows the value ranges of the main variables analyzed in SW affluent to the HSSF-CW systems throughout the experimental period.

TABLE 1. Average values and standard deviation of the main variables in six samples of swine wastewater affluent $\left(\mathrm{SW}_{\mathrm{A}}\right)$ to the $\mathrm{HSSF}-\mathrm{CW}$ systems.

\begin{tabular}{|c|c|c|c|c|c|c|c|c|}
\hline $\mathbf{M}$ & EC & COD & BOD & TSS & TN & $\mathbf{P}$ & $\mathbf{K}$ & $\mathbf{N a}$ \\
\hline PI & $\mathrm{dS} \mathrm{m}^{-1}$ & -----------. & 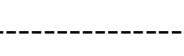 & ---------- n & $\mathrm{g} \mathrm{L}^{-1}$ & 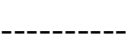 & --------- & -- \\
\hline $8.0 \pm 0.2$ & $3.81 \pm 0.38$ & $1.188 \pm 572$ & $818 \pm 570$ & $198 \pm 64$ & $437 \pm 73$ & $50 \pm 5$ & $79 \pm 12$ & $81 \pm 27$ \\
\hline
\end{tabular}

\section{Experiment conduction}

Cultivated plant species were Tifton 85 (Cynodon spp.) (HSSF-CW 2 and 5) and alligator weed (Alternanthera philoxeroides) (HSSF-CW 3 and 6), planted at a density of 20 planting holes $\mathrm{m}^{-2}$ and arranged in triangular spacing. At each planting hole, we planted four propagules of Tifton 85 and only one of alligator weed. No plant species was cultivated in HSSF-CW 1 and 4. Table 2 displays the operational characteristics of HSSF-CW based on $\mathrm{SW}_{\mathrm{A}}$ characteristics.

TABLE 2. Operational characteristics of HSSF-CW.

\begin{tabular}{|c|c|c|c|c|c|}
\hline & $\mathbf{Q}_{\mathbf{A}}$ & HDT & OLRs & $\operatorname{OLR}_{\mathrm{T}}$ & $\mathbf{S L R}_{\mathbf{T}}$ \\
\hline & $\left(\mathrm{m}^{3} \mathrm{~d}^{-1}\right)$ & (d) & --------------- & $\mathrm{g} \mathrm{m}^{-2} \mathrm{~d}^{-}$ & ----------- \\
\hline Average values & $0.069 \pm 0.014$ & $2.9 \pm 0.6$ & $56.4 \pm 11.4$ & 3,272 & 792 \\
\hline
\end{tabular}

Between the reservoir and metering pump outlets, there was a reduction in SW suspended solids concentration for two main reasons: deposition of a large part of solids at the storage reservoir bottom and filtration in a device coupled to the metering pump inlet valve (indispensable to avoid its obstruction). To accelerate HSSF-CW clogging process, part of the amount of solids retained in the storage/feeding system was applied weekly, thus enabling the recovery of part of the real load of solids contained in the raw SW. A volume of $1 \mathrm{~L}$ of solids deposited at the SW reservoir bottom was added weekly in each HSSF-CW. Solids collected at the reservoir bottom presented an average concentration of $21,611 \pm 4,070 \mathrm{mg} \mathrm{L}^{-1}$ in total suspended solids (TSS). Thus, the average weekly load of solids in each HSSF-CW was $117.245 \mathrm{~g}$, resulting in an average daily application of $16.749 \mathrm{~g} \mathrm{~m}^{-2} \mathrm{~d}^{-1}$.

SW application in HSSF-CW started on June 15, 2011. At the end of the experiment, on November 11, 2011, we harvested the plants determined dry matter productivity. For this, we 
collected plant shoot separately from each third of each HSSF-CW, and let it dry at $65{ }^{\circ} \mathrm{C}$ in a forced air circulation oven until reaching the constant mass.

\section{Determination of hydraulic conductivity $\left(K_{s}\right)$}

$K_{s}$ value in support medium of cultivated and non-cultivated HSSF-CW was determined in a punctual way along the system length and over the experimental period in order to assess the effects of vegetation, position, and time factors on this hydrodynamic property. During the experimental period (63 days), we performed five measurements.

The $K_{s}$ was measured in each HSSF-CW third by means of the installation of PVC pipes with $75 \mathrm{~mm}$ in diameter and $0.50 \mathrm{~m}$ in length, which worked as piezometers. These tubes were placed at the center of each HSSF-CW third, at a wet depth of $10 \mathrm{~cm}$. Measurements were carried out at distances of $0.33,1.00$ and $1.67 \mathrm{~m}$ from the system beginning. The variable load test (falling head test) was used with a downward water level similar to that used by PAOLI \& VON SPERLING (2013), but with a different geometry piezometer. The mathematical solution used was in accordance with HVORSLEV (1951). The $K_{s}$ values obtained represent vertical hydraulic conductivity, which is associated with the way the piezometer was installed.

Measurement procedure consisted of applying a hydraulic load of $0.40 \mathrm{~m}$ as a pulse by using a piezometer, observing the time required for water to infiltrate into $\mathrm{HSSF}-\mathrm{CW}$ porous medium. To measure the water level decay over time, a hydrostatic level transmitter HYTRONIC ${ }^{\circledR}$, model TSH/100M/P/02 (0 to 1 m.c.a.), was used connected to converter modules 7520 and A/D 7018 and subsequently to a computer. Every second water level was recorded. For data collection and storage, the software Sistema de Aquisição de Dados, developed by BATALHA (2011), was used. The liquid used for measurements was HSSF-CW effluent $\left(\mathrm{SW}_{\mathrm{E}}\right)$.

Clean gravel $K_{s}$ (without SW) was estimated by means of an HSSF-CW with the same dimensions as the other experimental units. At the center of each third of this HSSF-CW, piezometers with $75 \mathrm{~mm}$ in diameter and $0.50 \mathrm{~m}$ in length were also installed at a wet depth of 10 $\mathrm{cm} . K_{s}$ were measured at each third using clean water. The resulting average value corresponded to $K_{s}$ in a clean bed, without the presence of biofilm, solids, roots, stolons, and plant residues.

In the mathematical procedure proposed by HVORSLEV (1951), parameters from piezometer and from the curve $h / h_{0}$ versus time $(t)$ are used on a semi-logarithmic scale. According to this solution, $K_{s}$ can be obtained using [eq. (1)]:

$$
K_{s}=\frac{\pi d+11 H}{11 t_{37}} \times 100
$$

where,

$K_{s}$ is the saturated hydraulic conductivity $\left(\mathrm{m} \mathrm{s}^{-1}\right)$,

$d$ is the inner tube diameter $(\mathrm{m})$,

$H$ is the submerged tube height (m),

$t$ is the time corresponding to water level height $h(\mathrm{~s})$,

$t_{37}$ is the basic delay time (s) correspondent to the time elapsed until the water level reaches $37 \%$ of initial level, i.e. $h / h_{0}=0.37$,

$h_{0}$ is the initial water height inside the tube (m), and

$h$ is the water level height inside the tube at time $t(\mathrm{~m})$.

The $K_{s}$ measures were corrected to the reference temperature $\left(20^{\circ} \mathrm{C}\right)$ by using [eq. (2)]. The liquid temperature inside each $\mathrm{HSSF}-\mathrm{CW}$ was obtained from the reading on a mercury thermometer. Viscosity values used in the calculations were those referring to clean water obtained in tables available in the technical literature. 


$$
K_{s 20}=K_{e s}\left(\frac{\mu_{e}}{\mu_{20}}\right)
$$

where,

$K_{s 20}$ is the saturated hydraulic conductivity of liquid at a standard temperature of $20{ }^{\circ} \mathrm{C}\left(\mathrm{m} \mathrm{d}^{-1}\right)$,

$K_{e s}$ is the experimental saturated hydraulic conductivity $\left(\mathrm{m} \mathrm{d}^{-1}\right)$,

$\mu_{e}$ is the dynamic viscosity of water at ambient temperature $\left(\mathrm{kg} \mathrm{m}^{-1} \mathrm{~s}^{-1}\right)$, and

$\mu_{20}$ is the dynamic viscosity of water at $20{ }^{\circ} \mathrm{C}\left(\mathrm{kg} \mathrm{m}^{-1} \mathrm{~s}^{-1}\right)$.

\section{Experimental design}

The experiment consisted of three different treatments: non-cultivated HSSF-CW (SP), HSSF-CW cultivated with Tifton 85 (Cynodon spp.) (P1) and HSSF-CW cultivated with alligator weed (Alternanthera philoxeroides) (P2), installed in a split-split-plot design with treatments in the plots, each HSSF-CW third in the subplots, and assessment times in the sub-subplots. The experimental design was completely randomized design with two replications. Data were analyzed by means of analysis of variance and regression. For qualitative factor, averages were compared by using the Tukey's test at $10 \%$ probability level.

\section{RESULTS AND DISCUSSION}

Based on the analysis of variance of $K_{s}$ data, vegetation factor (absence of plants, Tifton 85 , and alligator weed) and the interaction of position and vegetation effects were significant at 10 and $5 \%$ probability, respectively. Position and time factors did not present an independent significant effect. No significant effect was also observed in the interactions between time and vegetation, time and position, and time and position and vegetation (Table 3).

TABLE 3. Summary of relative analysis of variance of $K_{s}$ in HSSF-CW non-cultivated (SP) and cultivated with Tifton 85 (P1) and alligator weed (P2).

\begin{tabular}{lcc}
\hline Source of variation & DF & Mean square \\
\hline Vegetation (V) & 2 & $4,952,972.0^{\circ}$ \\
Error (a) & 3 & $1,285,998.0$ \\
Position (P) & 2 & $31,908.2^{\mathrm{ns}}$ \\
$\mathrm{P} \times \mathrm{V}$ & 4 & $2,515,700.0^{*}$ \\
Error (b) & 6 & $960,356.8$ \\
Time (T) & 4 & $57,817.1^{\mathrm{ns}}$ \\
$\mathrm{T} \times \mathrm{V}$ & 8 & $40,653.0^{\mathrm{ns}}$ \\
$\mathrm{T} \times \mathrm{P}$ & 8 & $41,066.5^{\mathrm{ns}}$ \\
$\mathrm{T} \times \mathrm{P} \times \mathrm{V}$ & 16 & $38,625.2^{\mathrm{ns}}$ \\
Residual & 36 & $39,069.2$ \\
\hline CV plot & $53.93 \%$ & \\
CV subplot & $46.61 \%$ & \\
CV sub-subplot & $9.40 \%$ & \\
\hline
\end{tabular}

ns, *, and ${ }^{\circ}$ : not significant and significant at 5 and $10 \%$ probability level, respectively, by the $\mathrm{F}$ test.

$\mathrm{DF}$ - degrees of freedom; CV - coefficient of variation.

Even if the vegetation factor was significant, statistical analysis effect depended on position. For this reason, Table 4 displays the breakdown of this interaction. 
TABLE 4. Average values of $K_{s}\left(\mathrm{~m} \mathrm{~d}^{-1}\right)$ for combinations between vegetation (Tifton $85-\mathrm{P} 1$, and alligator weed $-\mathrm{P} 2$ ) and position in $\mathrm{HSSF}-\mathrm{CW}$.

\begin{tabular}{lccc}
\hline Treatment & \multicolumn{3}{c}{ Position } \\
\cline { 2 - 4 } & $1^{\text {st }}$ third & $2^{\text {nd }}$ third & $3^{\text {rd }}$ third \\
SP & $2,123 \mathrm{aA}$ & $2,682 \mathrm{aA}$ & $2,834 \mathrm{aA}$ \\
$\mathrm{P} 1$ & $2,390 \mathrm{aA}$ & $2,257 \mathrm{aAB}$ & $1,392 \mathrm{aB}$ \\
$\mathrm{P} 2$ & $1,824 \mathrm{aA}$ & $1,449 \mathrm{aB}$ & $1,973 \mathrm{aAB}$ \\
\hline
\end{tabular}

Means followed by the same letter do not differ significantly from each other at $10 \%$ significance level by the Tukey's test. Lowercase letters refer to lines and uppercase letters refer to columns.

According to the data presented in Table 4, no significant differences was observed between $K_{s}$ values obtained in different measurement positions, within the same HSSF-CW, i.e. no differences can be attributed between inlet, central, and outlet zones for any of the treatments applied. This is due, at least in part, to the relatively small dimensions of HSSF-CW used, which may have provided a rapid solid distribution throughout the porous medium, and to a possible effect of tank walls on the applied water flow during $K_{s}$ measurements. In addition, the hydrodynamic conditions of porous medium downstream of measuring point may possibly have influenced.

Although there were no differences in $K_{s}$ considering the measurement position in the systems, comparative studies of values found in HSSF-CW inlet and outlet zones have shown significant differences of this variable in relation to position. In a review on clogging, KNOWLES et al. (2011) reported 21 cases of distinct HSSF-CW, in which differences were identified between $K_{s}$ values measured in inlet and outlet regions, with an average reduction of $60 \%$. The authors attributed the porous medium obstruction to operational factors related to wastewater solids applied and chemical precipitates, introduction and accumulation of solid materials from the substrate, the growth of plant roots and biofilm, and plant residues presence in a porous medium.

In the study developed by PAOLI \& VON SPERLING (2013), longitudinal and transversal variations were observed in $K_{S}$ for both cultivated and non-cultivated systems. However, the authors obtained very low hydraulic conductivities when compared to those obtained in this study. In the inlet zones, cultivated HSSF-CW presented values from 7 to $11 \mathrm{~m} \mathrm{~d}^{-1}$ and from 67 to $70 \mathrm{~m} \mathrm{~d}^{-1}$ for those non-cultivated. In the outlet zones, cultivated systems presented $K_{s}$ values from 30 to $107 \mathrm{~m}$ $\mathrm{d}^{-1}$ and non-cultivated HSSF-CW presented a range from 198 to $324 \mathrm{~m} \mathrm{~d}^{-1}$. These results can be associated with a longer operating time of assessed systems (about two years), which allows a greater porous space occupation with solids from the applied wastewater, detached from the substrate, precipitated, and from the biofilm developed in the system. In other studies, $K_{s}$ heterogeneity has also been reported, as in PEDESCOLL et al. (2012) and RANIERI \& YOUNG (2012).

The substrate surface layer removal, a procedure inherent to the measurement method used, could also have been one of the factors responsible for non-detection of the position effect in $K_{s}$. Surface bed clogging has a great influence on hydraulic conductivity since it exerts a strong resistance to water infiltration in the medium (XIE et al., 2010). By removing the surface layer and introducing the measuring tube into the substrate, the resistance offered by this layer to wastewater flow is eliminated, providing only the measurement of a part of the subsurface hydraulic conductivity and not of the entire porous medium layer.

When comparing the treatment effect on $K_{s}$ values measured at same positions in HSSF-CW, the value measured at the second third of HSSF-CW cultivated with alligator weed was lower than that obtained at the second third of non-cultivated HSSF-CW. For HSSF-CW cultivated with Tifton $85, K_{s}$ value measured at the system's central part did not differ from any of those measured in the other systems. At the third, HSSF-CW cultivated with Tifton 85 presented lower $K_{s}$ in relation to non-cultivated $\mathrm{HSSF}-\mathrm{CW}$, which may be associated with pore occupation by plant roots.

Based on the results presented in Table 4, differences can be observed between $K_{s}$ values when considering the same measurement positions in $\mathrm{HSSF}-\mathrm{CW}$, with no significant differences 
between plant species. However, $K_{s}$ value found at the second third in HSSF-CW cultivated with alligator weed and that found at the third cultivated with Tifton 85 differed from those obtained in non-cultivated $\mathrm{HSSF}-\mathrm{CW}$, which is an indication that the cultivated plant species may influence the porous medium hydrodynamic characteristics.

Plants can maintain hydraulic conductivity over time by means of two main mechanisms: a) creation of preferential paths for water flow as a result of root growth and, particularly, rhizome penetration in the bed; and b) appearance of annular holes, or even cracks, at plant insertion points in the bed due to stem and leaf movement, resulting from wind action. This corroborates the results obtained by MATOS et al. (2010), who observed lesser pore obstruction of support medium in cultivated HSSF-CW than in those non-cultivated. Similarly, BRASIL \& MATOS (2008) observed an increase in $K_{s}$ value in HSSF-CW at the first 4 months of the experimental period in relation to the $K_{s}$ measured in clean gravel (without wastewater) due to support medium material uplift occurrence after vegetation establishment.

Regarding the influence of measuring position in bed on $K_{s}$ value, at the first third was observed that vegetation presence did not promote significant differences. This may be related to lower plant development at the inlet region and superficial layer removal, as recommended when using the method chosen to measure $K_{s}$. During the experimental period, plants of inlet region had lower density and height when compared to those cultivated at other HSSF-CW positions. This can be evidenced by the difference in dry matter productivity obtained for each third (Table 5). This impaired growth may be associated with lower root presence, which may mean a lower reduction in medium macroporosity.

A non-uniformity in root and biomass distribution along the bed length is related to a nonuniformity in $K_{s}$ distribution. In addition to roots, plant senescence can produce large amounts of plant residues, which will be deposited unevenly on the bed. Thus, where there is a higher plant incidence, there will be a greater contribution of plant-origin solids, and vice versa, which will influence the clogging process and, consequently, $K_{s}$ value measured.

TABLE 5. Dry matter productivity $\left(\mathrm{t} \mathrm{ha}^{-1}\right.$ ) for each third of cultivated HSSF-CW after 60-day cultivation.

\begin{tabular}{lccc}
\hline \multirow{2}{*}{ Plant } & \multicolumn{3}{c}{ Dry matter productivity $\left(\mathrm{t} \mathrm{ha}^{-1}\right)$} \\
\cline { 2 - 4 } & $1^{\text {st }}$ third & $2^{\text {nd }}$ third & $3^{\text {rd }}$ third \\
\hline Tifton 85 & 8.2 & 9.8 & 8.9 \\
Alligator weed & 6.0 & 7.4 & 6.7 \\
\hline
\end{tabular}

Although $K_{s}$ had no significant differences during the experimental period (63 days), it does not imply that the measurement method is not sensitive to these variations. In this sense, two main reasons can explain this fact. One is because the measurement method clearly alters substrate (support medium) conditions at the test site, as previously mentioned. Another might be due to an insufficient experimental time, leading to changes in $K_{s}$ in a porous medium which were perceptible by the method used. Figure 2 shows a graph with $K_{s}$ average values obtained over HSSF-CW operating time. 


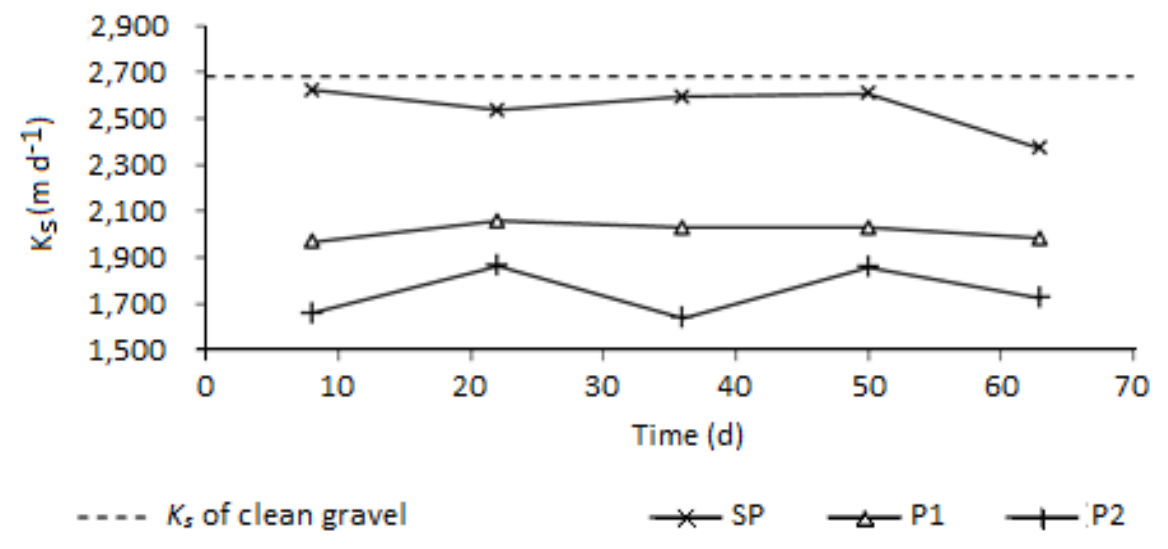

FIGURE 2. $K_{s}$ values obtained for clean gravel and non-cultivated HSSF-CW (SP) and cultivated with Tifton 85 (P1) and alligator weed (P2).

Figure 1 shows the difference caused by modifications provided in $K_{s}$ as the systems started operating. Comparing $K_{s}$ values obtained for clean gravel with $K_{s}$ average values of non-cultivated HSSF-CW, those cultivated with Tifton 85, and alligator weed, an average reduction of 5, 25, and $35 \%$ was observed, respectively.

Studies on $K_{s}$ modifications over time have been performed during longer periods of HSSFCW operation. BRASIL \& MATOS (2008) observed an increase in $K_{s}$ from 7,970 to $15,423 \mathrm{~m} \mathrm{~d}^{-1}$ after planting southern cattail in HSSF-CW filled with gravel $\# 0\left(\mathrm{D}_{60}=7.0 \mathrm{~mm}, \mathrm{Cu} \mathrm{D}_{60} / \mathrm{D}_{10}=1.6\right.$, and void volume of $48.4 \%$ ) as medium support. After 6.5 months of system operation for treating primary wastewater from domestic sewage, a decrease in $K_{s}$ to $9,144 \mathrm{~m} \mathrm{~d}^{-1}$ was observed, which is higher than that measured in clean gravel.

Solid introduction into the substrate from both SW and vegetation, as well as biofilm growth, led to a reduction in $K s$ for both cultivated and non-cultivated systems, as reported in the literature. According to LA VARGA et al. (2013), multiple local factors and conditions can influence solid accumulation and thus $K_{s}$ values. Therefore, each system presents a distinct response due to a set of factors, such as the applied TSS load, cultivated plant species, system operating time, wastewater characteristics, climatic conditions, etc.

TSS load applied in the studied HSSF-CW was higher than that usually reported in the literature. All systems received the same TSS load and each of them presented a distinct $K_{s}$ reduction (Figure 1). Thus, apparently, no direct relationship exists between a single factor, such as TSS rate, and $K_{s}$ variation. Similarly, not necessarily higher TSS loads imply in higher $K_{s}$ reductions, which is evidenced in several studies found in the literature. In this sense, in a study carried out by LA VARGA et al. (2013), whose systems were cultivated with Juncus effusus, $K_{s}$ presented average values of 56.4 and $67.5 \mathrm{~m} \mathrm{~d}^{-1}$ for $\mathrm{HSSF}-\mathrm{CW}$ inlet and outlet, respectively. These systems were used for 4.7 years for domestic sewage treatment at a TSS application rate of less than $9.98 \mathrm{~g} \mathrm{~m}^{-2} \mathrm{~d}^{-1}$. When applying a TSS rate of $1.5 \mathrm{~g} \mathrm{~m}^{-2} \mathrm{~d}^{-1}$ of the effluent from wastewater treatment generated in wine production, after 2.2 years of system operation, the values found were 137.1 and $131.1 \mathrm{~m} \mathrm{~d}^{-1}$ for HSSF-CW inlet and outlet, respectively. PEDESCOLL et al. (2013) assessed HSSF-CW systems cultivated with Phragmites australis in domestic sewage treatment. After 2.6 years, theses authors observed that $K_{s}$ value decreased from $484 \mathrm{~m} \mathrm{~d}^{-1}$ (PEDESCOLL et al., 2011a) to $28.3 \mathrm{~m} \mathrm{~d}^{-1}$ in an HSSF-CW that received an average TSS load of $9.0 \mathrm{~m}^{-2} \mathrm{~d}^{-1}$, and to $25.2 \mathrm{~m} \mathrm{~d}^{-1}$, in the initial parts of HSSF-CW systems that received double the SST load. Thus, $K_{s}$ variability is due to a set of factors, which interfere in a concomitant and integrated way. Moreover, the composition of accumulated material, responsible for clogging, is as important as its quantity (KNOWLES et al., 2011; POZZO-MORALES et al., 2013) regarding $K_{s}$ reduction. 


\section{CONCLUSIONS}

Based on the results, no difference was observed in $K_{s}$ values obtained in cultivated and noncultivated HSSF-CW, over the experimental period. However, a $K_{s}$ reduction was observed in relation to the value obtained in the HSSF-CW that did not receive swine wastewater. Similarly, no spatial variation was observed in $K_{s}$ along the length of HSSF-CW systems. Conditions established in $K_{s}$ measurement method, $\mathrm{HSSF}-\mathrm{CW}$ size, and short-period experiment conduction may have influenced the results.

\section{ACKNOWLEDGEMENTS}

The authors would like to thank the Brazilian agencies CNPq and FAPEMIG for their support to the research.

\section{REFERENCES}

APHA - AMERICAN PUBLIC HEALTH ASSOCIATION; AWWA - AMERICAN WATER WORKS ASSOCIATION; WEF - WATER ENVIRONMENT FEDERATION. Standard methods for the examination of water and wastewater. $22^{\text {nd }}$ ed. Washington, D.C.: American Public Health Association, 2012. 1046p.

BATALHA, B.R. Temperatura do dossel vegetativo da cana-de-açúcar sob diferentes condições meteorológicas e potenciais de água no solo. 2011. 142 f. Dissertação (Mestrado em Meteorologia Agrícola) - Universidade Federal de Viçosa, Viçosa, 2011.

BRASIL, M.S.; MATOS, A.T. Avaliação de aspectos hidráulicos e hidrológicos de sistemas alagados construídos de fluxo subsuperficial. Engenharia Sanitária e Ambiental, Campina Grande, v.13, n.3, p.323-328, 2008.

COTA, R.S.; VON SPERLING, M.; PENIDO, R.C.S. Tracer studies and hydraulic behaviour of planted and un-planted vertical-flow constructed wetlands. Water Science and Technology, Oxford, v.64, n.5, p. 1056-1063, 2011.

FIA, R. MATOS, A.T.; MATOS, M.P.; ABREU, E.C.; FIA, F.R.L. Tratamento das águas do processamento dos frutos do cafeeiro em filtro anaeróbio seguido por sistema alagado construído: I - remoção de matéria orgânica. Engenharia Agrícola, Jaboticabal, v.30, n.6, p.1191-1202, 2010.

FU, G.; ZHANG, J.; CHEN, W.; CHEN, Z. Medium clogging and the dynamics of organic matter accumulation in constructed wetlands. Ecological Engineering, Oxford, v.60, p.393-398, 2013.

HVORSLEV, M.J. Time lag and soil permeability in ground water observations. Vicksburg, Mississippi: U.S. Army Corps of Engineers Water-way Experimentation Station, 1951. (Bulletin, 36).

KNOWLES, P.R.; GRIFFIN, P.; DAVIES, P.A. Complementary methods to investigate the development of clogging within a horizontal subsurface flow tertiary treatment wetland. Water Research, Oxford, v.44, p.320-330, 2010.

KNOWLES, P.; DOTRO, G.; NIVALA, J.; GARCÍA, J. Clogging in subsurface-flow treatment wetlands: occurrence and contributing factors. Ecological Engineering, Amsterdam, v.37, p.99$112,2011$.

LA VARGA, D.; DÍAZ, M.A.; RUIZ, I.; SOTO, M. Avoiding clogging in constructed wetlands by using anaerobic digesters as pre-treatment. Ecological Engineering, Amsterdam, v.52, p.262-269, 2013.

MATOS, A.T.; FREITAS, W.S.; LO MONACO, P.A.V. Eficiência de sistemas alagados construídos na remoção de poluentes de águas residuárias da suinocultura. Revista Ambiente e Água, Taubaté, v.5, n.2, p.119-132, 2010. 
NIVALA, J.; KNOWLES, P.; DOTRO, G.; GARCÍA, J.; WALLACE, S. Clogging in subsurfaceflow treatment wetlands: measurement, modeling and management. Water Research, Oxford, v.46, p.1625-1640, 2012.

PAOLI, A.C.; VON SPERLING, M. Evaluation of clogging in planted and unplanted horizontal subsurface flow constructed wetlands: solids accumulation and hydraulic conductivity reduction. Water Science and Technology, Oxford, v.67, n.6, p.1345-1352, 2013.

PEDESCOLL, A.; CORZO, A.; ÁLVAREZ, E.; GARCÍA, J.; PUIGAGUT, J. The effect of primary treatment and flow regime on clogging development in horizontal subsurface flow constructed wetlands: An experimental evaluation. Water Research, Oxford, v.45, n.12, p.35793589, 2011a.

PEDESCOLL, A.; PASSOS, F.; ALBA, E.; GARCIA, J.; PUIGAGUT, J. Mechanical resistance properties of gravel used in subsurface flow constructed wetlands: implications for clogging. Water Science and Technology, Oxford, v.63, n.9, p.1801-1807, 2011b.

PEDESCOLL, A.; KNOWLES, P. R.; DAVIES, P.; GARCÍA, J.; PUIGAGUT, J. A comparison of in situ constant and falling head permeameter tests to assess the distribution of clogging within horizontal subsurface flow constructed wetlands. Water, Air, and Soil Pollution, Dordrecht, v.223, n.5, p.2263-2275, 2012.

PEDESCOLL, A.; SIDRACH-CARDONA, R.; SÁNCHEZ, J.C.; CARRETERO, J.; GARFI, M.; BÉCARES, E. Design configurations affecting flow pattern and solids accumulation in horizontal free water and subsurface flow constructed wetlands. Water Research, Oxford, v.47, n.3, p.14481458, 2013.

POZO-MORALES, L.; FRANCO, M.; GARVI, D.; LEBRATO, J. Influence of the stone organization to avoid clogging in horizontal subsurface-flow treatment wetlands. Ecological Engineering, Oxford, v.54, p.136-144, 2013.

PRATA, R.C.C.; MATOS, A.T.; CECON, P.R.; LO MONACO, P.A.V.; PIMENTA, L.A. Tratamento de esgoto sanitário em sistemas alagados construídos cultivados com lírio-amarelo. Engenharia Agrícola, Jaboticabal, v.33, n.6, p.1144-1155, 2013.

RANIERI, E.; YOUNG, T.M. Clogging influence on metals migration and removal in sub-surface flow constructed wetlands. Journal of Contaminant Hydrology, New York, v.129-130, n.0, p.3845, 2012.

XIE, X.L.; HE, F.; XU, D.; WU, Z. Hydrodynamic aspects of particle clogging in the simulated vertical flow constructed using sand river as substrate. Fresenius Environmental Bulletin, Freising, v.19, n.11, p.2567-2575, 2010.

XU, Q.; CUI, L.; ZHANG, L.; LI, ZIXIA; GUANGWEI, Y. The Effect of two factor combination of three kinds of loading on the soil clogging in vertical flow constructed wetland. Frontier of Environmental Science, Beijing, v.2, n.4, p.56-63, 2013. 